\title{
Commentary: Orbital Dynamics for National Security Lawyers
}

Jordan Foley

Georgetown University Law Center

\begin{abstract}
Space is harsh, and does not operate like terrestrial environments. For national security lawyers and those advising commanders in operational law choices, drawing direct comparisons to maritime, littoral, and air regimes is a flawed assumption. Space is not uniform. Space domains impose different constraints and support different operating options. The overall goal of this article is to demystify and help normalize outer space, so national security lawyers can add value to the overall mission. By introducing Juris Doctors to conceptual insights of space physics implications, they can better develop frameworks for understanding operational choices.
\end{abstract}

Keywords: orbital dynamics, national security lawyers, space, LEO, GEO, HEO, MEO

\section{Comentario: Dinámica orbital para abogados de seguridad nacional}

\section{RESUMEN}

El espacio es duro y no funciona como los entornos terrestres. Para los abogados de seguridad nacional y aquellos que asesoran a los comandantes en las elecciones de leyes operativas, establecer comparaciones directas con los regímenes marítimo, litoral y aéreo es una suposición errónea. El espacio no es uniforme. Los dominios espaciales imponen diferentes restricciones y admiten diferentes opciones operativas. El objetivo general de este artículo es desmitificar y ayudar a normalizar el espacio exterior, para que los abogados de seguridad nacional puedan agregar valor a la misión general. Al introducir a los Juris Doctor en conocimientos conceptuales de las implicaciones de la física espacial, pueden desarrollar mejor los marcos para comprender las opciones operativas.

Palabras clave: dinámica orbital, abogados de seguridad nacional, espacio, LEO, GEO, HEO, MEO, doctores juris 


\section{评论文：国防律师应理解的轨道动态}

\section{摘要}

太空是恶劣的, 其运作模式不同于陆地环境。对国防律师和 那些为长官提供操作性法律选择咨询的人士而言, 将太空与 海上、沿海、航空系统作直接比较是一个有瑕疪的假设。太 空并不是均一的。太空领域施加了不同限制, 并支持不同的 操作选择。本文的总体目标是阐明并帮助将外太空正常化, 以便国防律师能对整体太空任务作贡献。通过让职业法律博 士（Juris Doctors）理解有关太空物理影响的概念，他们 能更好地制定用于理解操作选择的框架。

关键词: (太空) 轨道动态, 国防律师, 太空, LE0, GEO, HEO, ME0, 职业法律博士

Luke Skywalker: Why don't you outrun them? I thought you said this thing was fast.

Han Solo: Watch your mouth, kid, or you're going to find yourself floating home. We'll be safe enough once we make the jump to hyperspace ...

Obi Wan Kenobi: How long before you make the jump to lightspeed?

Han: It'll take a few moments to get the coordinates from the navicomputer.

Luke: Are you kidding — at the rate they're gaining?

Han: Traveling through hyperspace isn't like dusting crops ...

Star Wars Episode IV - A New Hope

$\mathrm{I}$ 'll be checking a lifelong goal off my list: quote Star Wars in an academic publication. That wasn't just for a laugh. Han is right-“"Traveling through hyperspace isn't like dusting crops." Science fiction or not, there is a valuable lesson in the old smuggler's statement. Space is harsh and does not operate like terrestrial environments. For the national security lawyer and those advising commanders in operational law choices, drawing direct comparisons to maritime, littoral, and air regimes is a flawed assumption. Space 
is not uniform. Space domains impose different constraints and support different operating options.

"Orbital Dynamics for National Security Lawyers" is a purposefully "dry" title. The overall goal of this article is to demystify and help normalize outer space, so national security lawyers can add value to the overall mission. By introducing Juris Doctors to conceptual insights of space physics implications they can better develop frameworks for understanding operational choices. While the title may be dry, I hope my sci-fi references make a discussion on astrodynamics more palatable for those who took a look at undergraduate calculus and ran the other way.

There's a lot to cover. Orbital dynamics is just one subset of the many $\mathrm{PhDs}$ associated with the engineers, scientists, and physicists working in the field. In 2020, we are starting to see different professions flock to outer space for lucrative opportunities-enter stage right, businesspeople and lawyers. The proliferation of private space companies, like SpaceX and Blue Origin, are reshaping a modus operandi thought once to be the sole province of government entities. That's because space is an expensive medium. Pre-launch costs are in the tens of millions of dollars and take years to plan and execute. Satellites require an extensive ground support structure, including control centers and command and control infrastructure. SpaceX breaking onto the stage shows private companies can compete in space commerce-with business opportunities comes the need for legal support.
International law directs State and non-State actors' conduct in outer space. You might be familiar with the 1967 Outer Space Treaty (OST). We can call this the "magna carta" of Space Law. It's foundational. However, space law has been around since even before then. Numerous earlier UN Resolutions expressed legal principles for outer space prior to the OST, but they did not become binding until incorporated into a treaty in 1967. Every spacefaring state is a party to the OST, and several provisions have become principles of customary international law, too.

There's quite a time gap between the last crewed moon landing in 1972 and now, yet the topic of space law has never been more important. How do we manage private actor's and investor's expectations in this domain? How do we think about military forces in outer space? After all, this past year has seen the establishment of the U.S. Space Force and significant private sector achievements in outer space. So, it's not the Millennium Falcon jumping to hyperspace, but we are approaching an era of increased operations in outer space.

Believe it or not, there is a lack of international consensus on how we approach space law. Some believe a carefully framed legal order should be established, potentially through an international leasing system modeled on the United Nations Convention on the Law of the Sea (UNCLOS), to preserve the original goals and purposes of the OST during this new space age. Others are skeptical about any regime and believe most proposals would be rejected by major spacefaring countries. 
But, at the very least, there has to be consensus on where outer space begins. Wrong. The start of outer space is not as clear as you might assume. The distance between Earth and space is about 62 miles (100 kilometers), which is called the Karman line. By general accord, the Karman line is the altitude where suborbital space begins or where the planet's boundary ends. In other words, it represents the border between the Earth's atmosphere and outer space. The Karman line is conventionally used as the start of outer space in space treaties and for aerospace records keeping. Historically, the lowest satellite orbits have had perigees as low as $80-90 \mathrm{~km}$. The U.S. Air Force actually considered all X-15 flights above $80 \mathrm{~km}$ as astronautical flights and gave those pilots astronaut wings. There have been objections, particularly in the United States, to defining any legal boundary of space on the grounds that it could cause disputes about airspace violations below the boundary, or that too high a boundary could inhibit future space activities.

In Carl Sagan's science fiction novel Contact, which was later adapted to a movie bearing the same title, the main character played by Jodi Foster exclaims at the grandeur of outer space, "No words to describe it. Poetry! They should have sent a poet." If you are 0 for 2 now with movie references, you have some mandatory viewing after you're done reading. Sending a poet on this mission to capture extraterrestrial beauty in words is an interesting proposition. Of course, there will be many times we will encounter legal issues in outer space, and I don't think any- one would cry, "We should have sent a lawyer!" - but we are going to need lawyers. In particular, national security lawyers will be vital. It is about time to think about many aspects of space law. The focus of this article is how we equip national security lawyers with the tools they need to understand outer space and provide valuable legal advice for those companies and warfighters dependent upon their services.

Lawyers becoming experts in a technical field is not a novel concept. For example, lawyers practicing in medical malpractice have more knowledge about medical procedures and doctors' conduct than a layman, but at the same time, very few of those attorneys have an M.D. In medical malpractice cases, lawyers will still lean on experts, such as physicians in that particular field, to inform their arguments. To ask an attorney to be an expert in cardiothoracic and neurological surgery while maintaining proficiency in the law doesn't seem reasonable. However, in preparing for a particular case, we expect that attorney to be knowledgeable. After all, advocates must package and present complex material to a judge or jury. Just like a medical malpractice attorney must understand general surgery as it pertains to the case, lawyers involved in space law must understand orbital mechanics. I am not asking an attorney to, like a NASA engineer, use Keplerian elements in a two-line element set to maintain location information on all man-made objects in Earth's orbit. I am just proposing a training module that gets a lawyer up to speed on the space environment like those medical 
malpractice lawyers preparing for their next big, technical case. As a J.D. candidate, Navy Space Cadre Operations Officer, former Nuclear Submariner, and future JAG, I am positioned to offer some sort of well-packaged training for national security lawyers. This article is me beginning my quest to encourage all lawyers involved in space law to seek to understand the physics. In starting with orbital dynamics, we are drinking from a firehose, but I'm trying to slow the flow. Let's give it a whirl, and the next sections will hopefully have you walking away with newfound knowledge and desire to learn more about outer space.

Let's say it out loud, "Orbits are complex." Space is not "uniform" and orbits serve different functions. Because different orbits bring different utilities and problems, we need to plan our missions accordingly. Not to mention, changing orbital domains is difficult, so planning occurs pre-launch. Once on orbit, satellite path is largely determined by physics and not the operator, so we need to understand how the space environment will impact the spacecraft or else we will see limited functionality. The orbits we will focus on are Low Earth Orbit (LEO), Mid Earth Orbit (MEO), Geosynchronous and Geostationary Orbit (GEO), and Highly Eccentric Orbit (HEO). I don't have a pneumonic to remember these by like we had in grade school for the planets: "My Very Educated Mother Just Served Us Nine ..."-sorry, Pluto. However, the names are pretty descriptive. Let's start with the orbit closest to Earth.

LEO is a nearly circular orbit below $1,500 \mathrm{~km}$ altitude. LEO satellites travel $\sim 43,000 \mathrm{~km}$ in 90 minutes, without effort. A major feature is this orbit is close to the ground, so cheap launches get spacecraft into LEO. It is a relatively benign radiation environment with low atmospheric drag. A spacecraft in LEO will gain eventual global coverage. Common uses of LEO are for imaging, weather, and communications.

MEO consist of orbits between LEO and GEO, often at 20,000 km. Some major features of MEO are that there is good continuous coverage with multiple satellites, but it is a harsh radiation environment. The primary use of MEO is for navigation. This orbit is where the GPS constellation lives.

GEO consists of circular equatorial orbits near $35,000 \mathrm{~km}$ altitude. A major feature of GEO is its continuous regional coverage, but its high launch costs and great distance from earth make it a challenging orbit to reach. Common uses are for navigation, communication, weather, and imaging. While geosynchronous satellites can have any inclination, the key difference to geostationary orbit is the fact that they lie on the same plane as the equator. For a constant ground track, satellites will be in geostationary orbit. The difference is subtle, but important in understanding this orbit's utility. For example, geostationary communication satellites are useful because they are visible from a large area of the Earth's surface, extending $81^{\circ}$ away in both latitude and longitude. They appear stationary in the sky, which eliminates the need for ground stations to have movable antennas. See Fig 1. GEO Satellite Ground Coverage below. 


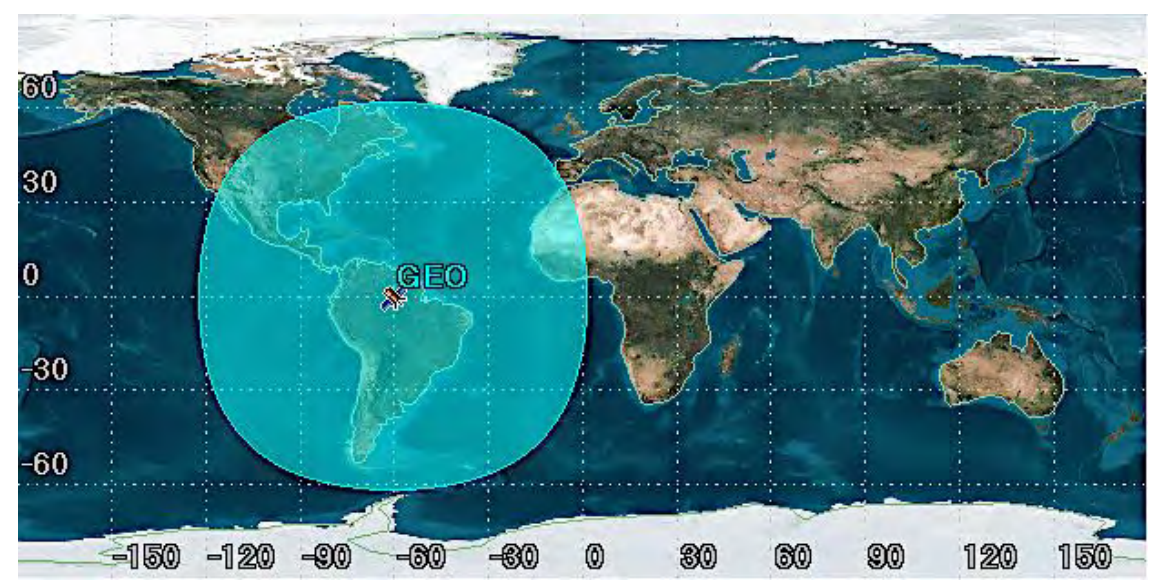

Fig 1. GEO Satellite Ground Coverage

HEO has orbits with altitude of perigee (defined as the point in the orbit of the moon or a satellite at which it is nearest to the earth) near LEO and altitude of apogee (defined as the highest point in the development of something; a climax or culmination) near GEO. Some features of HEO are long dwell times at apogee, and apogee can provide polar coverage. Most common uses are communications and transfer orbits from LEO to GEO.

Let's be clear. Getting from orbit to orbit once in space is not easy. As you saw, distances are vast and require a lot of fuel. Fuel is important in space. Typical spacecraft do not carry enough fuel to allow frequent dramatic orbit changes. The fuel carried is mostly to counteract orbit perturbations, also known as "station keeping." Fuel is often the limiting factor for satellite lifetime. Large changes must be preplanned as part of launch and operating budget. Orbit changes can be just a one-time expense to attain desired orbit. Remember that distance is thought about differently in space, so moderate altitude changes are actually hundreds of kilometers. Overall, orbit changes are costly and not simple.

As you can see, each orbit lends itself to different missions based on coverage and rotation. HEO, with its long dwell times at apogee and polar coverage, is a good orbit for optical spy satellites focused on that region. With their near continuous coverage, GEO makes for a great orbit for launch detection satellites. LEO is the cheapest and easiest orbit to enter, so many spacecrafts live here out of necessity, but continuous coverage can be achieved with multiple satellites. MEO (See Figure 2 below) is where GPS satellites orbit, because each satellite circles the Earth twice a day, and with an expandable 24-slot satellite constellation, GPS gets constant coverage.

There are also many classifications of orbits which vary in distance and synchronicity. Understanding LEO, MEO, GEO, and HEO are different distances from Earth is important, but we need to also think about the spacecraft 


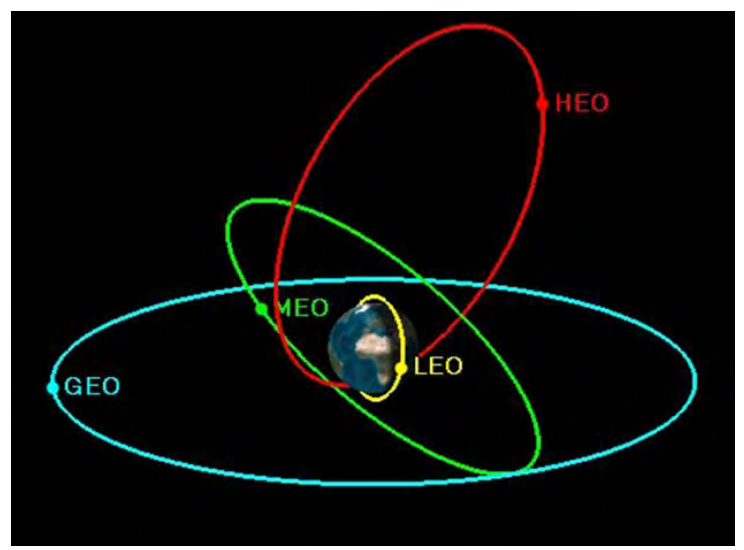

Figure 2. MEO Satellite Ground Coverage

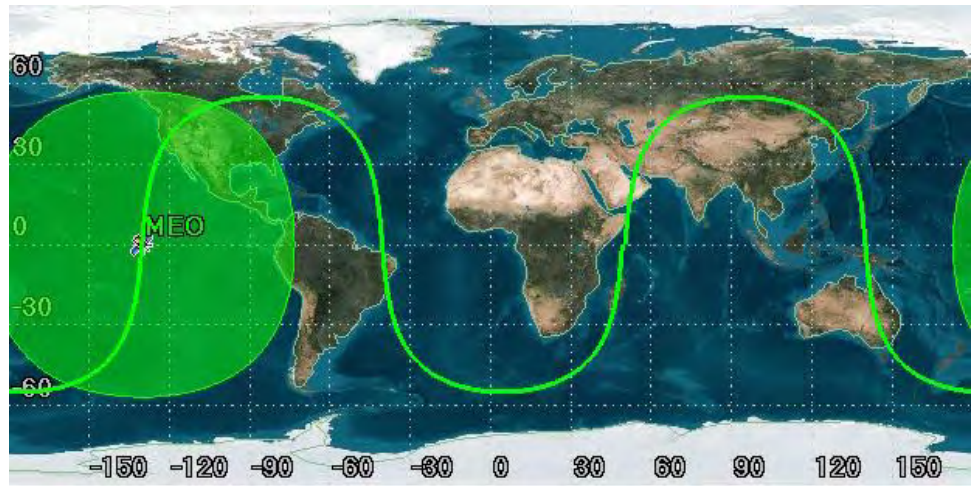

Figure 3. Summary Graphic of Orbits

in orbit and how many times it will orbit Earth. This is called a synchronicity classification. Not only do we consider which orbit, but also the number of times that orbiting body will pass over a point on earth. For example, the large majority of imaging sensors are on sun-synchronous orbits. This orbit allows the satellite to fly over the same area at the same time of day and provide nearly global coverage over a period of typically one to two weeks.

Think of synchronicity of orbits as the number and frequency of rotations around Earth. That is a pretty simplistic way to understand these classifications, but for our purposes we just need to be able to define the types of synchronicity classifications and the benefits they bring. This means the track of the satellite, as seen from the central body, will repeat after a fixed number of orbits. We will discuss synchronous, semi-synchronous, and sunsynchronous orbits. A synchronous orbit is an orbit in which a body (usually a satellite) has a period equal to the average rotational period of the body being orbited (usually a planet) and in the same direction of rotation as that body. Simply put, a synchronous orbit is an orbit in which the orbiting object 
(for example, an artificial satellite or a moon) takes the same amount of time to complete an orbit as it takes the object it is orbiting to rotate once.

A semi-synchronous orbit is an orbit with a period equal to half the average rotational period of the body being orbited, and in the same direction as that body's rotation. For Earth, a semi-synchronous orbit is considered a medium Earth orbit, with a period of just under 12 hours, like the GPS constellation in MEO.

A sun-synchronous orbit (also called a helio-synchronous orbit) is a nearly polar orbit around a planet, in which the satellite passes over any given point of the planet's surface at the same local mean solar time. A sun-synchronous orbit is useful for imaging, spy, and weather satellites, because every time that the satellite is overhead, the surface illumination angle on the planet underneath it will be nearly the same. This consistent lighting is a useful characteristic for satellites that image the Earth's surface in visible or infrared wavelengths, such as weather and spy satellites; and for other remote-sensing satellites, such as those carrying ocean and atmospheric remote-sensing instruments that require sunlight. For example, a satellite in sun-synchronous orbit might ascend across the equator twelve times a day each time at approximately 1400 mean local time.

If you're a lawyer reading this, you're probably asking yourself, "Why am I learning about this?" I am glad you asked. While space is vast, that does not mean two satellites will never col- lide causing a liability issue. In fact, we had a collision about ten years ago. In February 2009, Cosmos 2251, an inactive Russian satellite, collided with an active commercial communications satellite operated by U.S.-based Iridium Satellite LLC. The incident occurred approximately $800 \mathrm{~km}$ above Siberia. The collision produced almost 2,000 pieces of debris and many thousands of pieces more that are too small to track. Much of this debris will remain in orbit for decades or longer, posing a collision risk to other objects in LEO. This was the first-ever collision between two satellites in orbit, and it served as a wakeup call for the entire space community to the threat that space debris poses to active satellites as well as of the longterm negative impact catastrophic collisions can have on the space environment. The Liability Convention dictates that for damages which occur on orbit, fault must be determined. However, a legal definition does not currently exist for fault within the context of the Convention. The Cosmos-Iridium collision forced the space community to come to grips with the reality of today's space environment.

This is where our medical malpractice analogy diverges. In medical malpractice cases, expert witnesses provide input on the defendant's actions with respect to current medical standards and procedures. The attorneys in those cases are also relying on a wealth of case law, both State and Federal. In space law, we do not have case law. This field of law is predominantly governed by treaties. Without case law and only limited treaties, understanding the space 


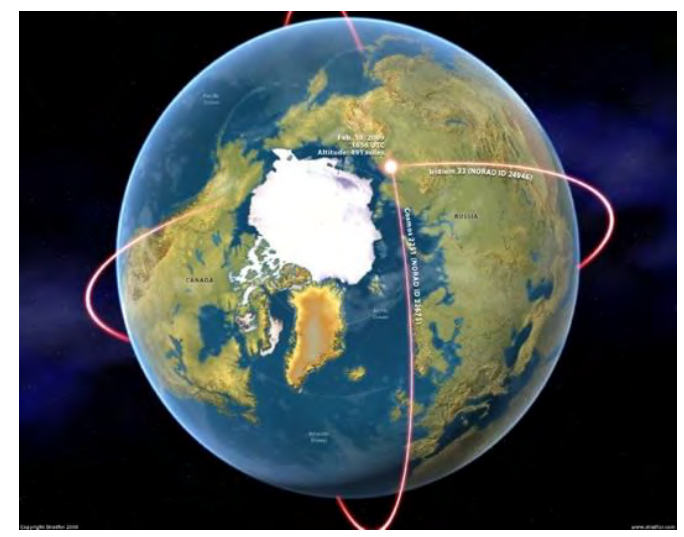

Figure 4. Cosmos-Iridium Collison

environment is crucial. For one, if you did not know there were different orbits with different characteristics, you'd have a rough time speaking up for your client. Not to mention, your client, someone well educated in the field, might lose faith in your abilities. Lawyers need to be more knowledgeable about the space operating environment to properly apply the existing legal regime or develop novel legal concepts.

From a national security perspective, space capabilities have proven to be a significant force multiplier when integrated into military operations. Countries must protect assured access through the synergy of cyberspace, space, and electronic operations. Joint forces rely on space assets and capabilities such as intelligence, surveillance, and reconnaissance. Formalizing the U.S. Space Force means more national security lawyers will need to be well versed in not only orbital dynamics but understanding the space environment.

On December 20, 2019, the United States Space Force (USSF) became the sixth branch of the Armed Forces. The
Space Force was established within the Department of the Air Force with the enactment of the 2020 National Defense Authorization Act. The Secretary of the Air Force is responsible for organizing, training, and equipping the Space Force as a separate, distinct military uniformed service. U.S. Space Command (SPACECOM) is a geographic combatant command (CCMD) with responsibility for fighting anywhere above $100 \mathrm{~km}$. "So just as we have recognized land, air, sea and cyber as vital warfighting domains, we will now treat space as an independent region overseen by a new unified, geographic combatant command," President Donald Trump said at a ceremony standing up SPACECOM. In defining SPACECOM's area of responsibility, U.S. policy begins this CCMD's duties at the Karman line.

From pre-launch (before a spacecraft leaves the ground) to orbit (the spacecraft enters outer space and begins to rotate around Earth), the space environment challenges all spacebased missions. After reading this brief overview of orbital dynamics, we now 
understand that space is not "uniform" and orbits serve different functions. Orbits are complex, but the major takeaway is they are different and offer advantages and disadvantages for certain missions. Understanding the differences between orbits is an important first step in understanding why some orbits are preferred for certain missions. Adversaries, both State and non-State actors, will exploit the availability of space-based capabilities to support their operations. In keeping with the principles of joint operations, this makes it incumbent on the U.S. to deny adversaries the ability to utilize space capabilities and services. To that extent, the U.S. military is orga- nized to meet its objectives in space. National security lawyers should be equally equipped to enable space missions.

"Traveling through hyperspace isn't like dusting crops," and space law is not like the law of the sea or any other terrestrial law. The new space age is placing unique requirements on people and industries formerly unassociated with the space race. National security lawyers must become technically proficient to best advocate for clients. Whether these lawyers are on the D.C. beltway or beyond, the law will be better formed by advocates who understand the operating domain of outer space.

\section{References}

Understanding Space, An Introduction to Astronautics (4th Edition), Dr. J. J. Sellers. (ISBN: 978-0-07-340775-3)

NASA Human Space Flight website (https://spaceflight.nasa.gov/realdata/sightings /SSapplications/Post/JavaSSOP/SSOP_Help/tle_def.html)

AU-18 (September 2009), Air University Space Primer (http://space.au.af.mil/au18-2009/index.htm)

NASA Website (https://www.nasa.gov/centers/kennedy/launchingrockets/sites. html)

Roger D. Launius, Historical Dimensions of the Space Age, Space Policy 16 (2000) Space Policy Directive-4 (SPD-4)

Joint Publication 3-14 (JP 3-14) Space Operations, Department of Defense, (April 2018)

Chapter 2 Space Operations and the Joint Functions, pp. II-1 - II-8

DOD Directive 4650.05 Positioning, Navigation, and Timing, (January 2019) 
Defense Space Strategy Summary, Department of Defense, (June 2020)

Nathan C. Goldman, American Space Law: International and Domestic, Iowa State University Press, 1988. Chapter 9, Evolution of Space Law, pp. $164-172$

AU-18 Space Primer, prepared by Air Command and Staff College Space Research Electives Seminars, Air University Press, Maxwell Air Force Base, Alabama (September 2009). Chapter 3 Current Space Law and Policy, pp. 43 - 59 